\title{
Sanitary Paper Consumption: A Material Stocks and Flows Analysis at Fenner Hall, 2012
}

\author{
Huan Zheng, Yale Wong
}

\section{Abstract}

The need for humanity to move towards a more sustainable future is widely recognised. This transition will require a reduction in the consumption of everyday products, such as sanitary paper. This material stocks and flows analysis explores the use of toilet paper and paper towels at Fenner Hall, a residential community of 507 students at The Australian National University, Canberra. A combination of quantitative and qualitative research methods are used to develop an inputs-processes-outputs model of sanitary paper, consistent with the systems thinking ethos of human ecology. This essay discusses the input flows of the material, before presenting the results of the seven-day data collection process. Daily sanitary paper consumption is estimated to be 70 grams on average per resident, and annual consumption 12.1 tonnes for the entire Fenner Hall community. The study then examines the output flows of toilet paper through the sewerage system, and paper towels through general waste collection. The results of the empirical evidence suggest some gender and temporal variation in the use of sanitary paper, which together with the free nature of this resource, offer potential directions for future research into human behaviour.

\section{Introduction}

Given that 70 per cent of the world's population will live in urban agglomerations by 2050 (United Nations Children's Fund (UNICEF), 2012), the notion of sustainability being won and lost in cities holds true (Bai, 2010). As such, it is imperative that human activities in urban systems are revisited, through reference to the urban metabolism metaphor, which consists of upstream inputs, processes and downstream output. Material stocks and flows analyses have proven to be an effective outputs of studying the ecosystem service impacts of goods and services, which is important theoretically and practically for the 
achievement of broader sustainability objectives. A sector of such importance is the pulp and paper industry, recognised by Sundin et al. (2001) as having farreaching significance for the triple bottom line objectives of social, economic and environmental sustainability. Not only is paper an indispensable consumable of modern human life, but the global annual consumption of 300 million tonnes has fostered the emergence of global supply chains, according economic benefits to developed and developing countries alike (Ververis et al., 2004: 245). Further, the high system energy requirement in the life cycle of paper contributes to its adverse environmental impacts, resulting in deforestation and greenhouse gas emissions, which have implications for climate change and biodiversity (Martin, 2007, Sundin et al., 2001).

Sundin et al. (2001) categorise paper products into six main grades, according to their end-use purposes: newsprint, graphic papers, corrugating materials, packaging and board, sanitary and household paper, and other paper and board. The focus of this study's material stocks and flows analysis is on sanitary and household paper products, namely toilet paper and paper towels. This is examined through a case study of sanitary paper consumption at Fenner Hall, a residential community at The Australian National University (ANU), Canberra. The sampled population differs from the wider Australian public, being a community of students, whose behaviour may also be affected by the sanitary paper being provided essentially for free. Firstly, this article explores the background and context of sanitary paper production, use and disposal in the Australian Capital Territory (ACT) region, with reference to its significance in everyday life. Through the presentation of an influence diagram illustrating the variables affecting sanitary paper consumption, this study then overviews the system boundary and methods used in the data collection. Next, the essay examines the inputs-processes-outputs model of sanitary paper with reference to the interdependency of each factor in a systemic approach. The essay examines the results of the analysis, and offers a discussion of the potential weaknesses and limitations of the project, as well as the implications of the research findings on urban sustainability. The systems thinking and holistic approach undertaken in this study pay homage to the complexity of interactions between humans and the urban environment. 


\section{Background and Context}

From production to use to waste management, the full life cycle of paper products features eight main stages of transformation, as illustrated in Figure 1.

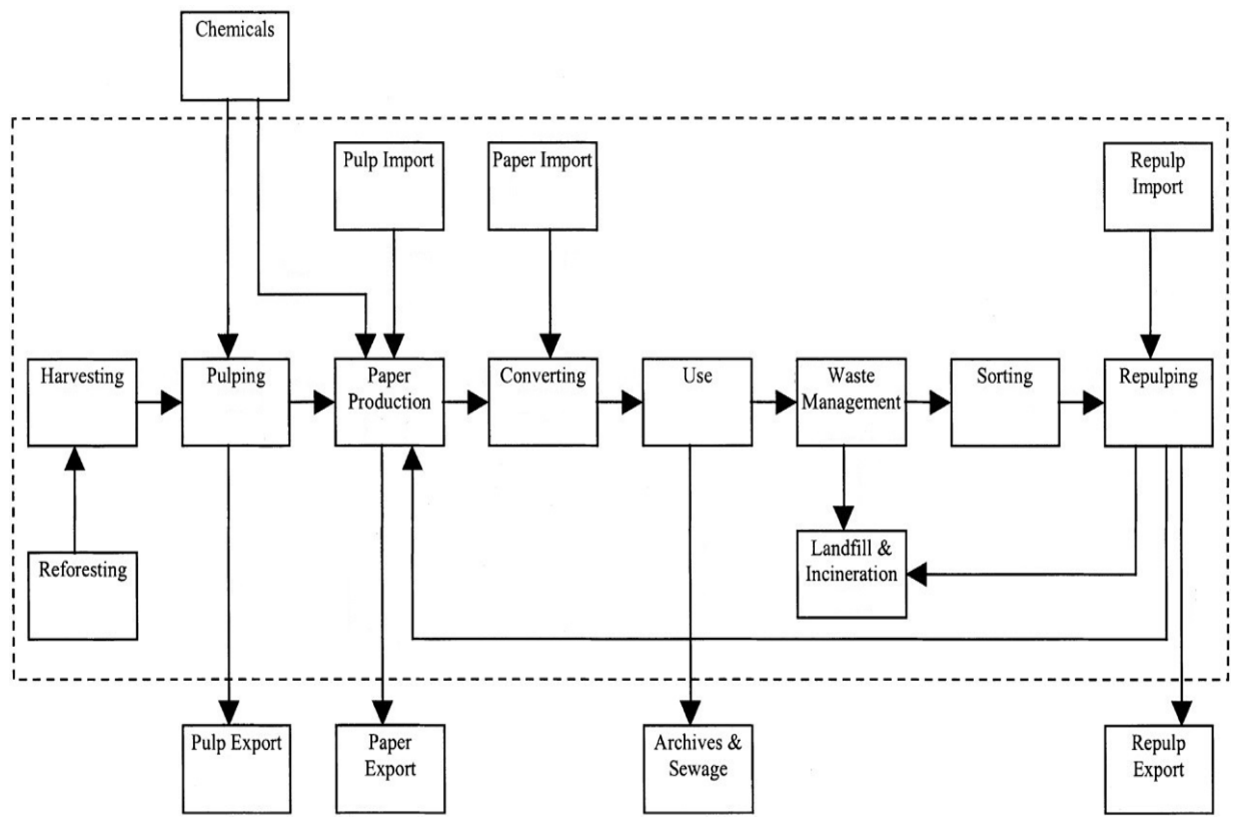

Figure 1: The typical life cycle of paper

Source: Adapted from Sundin et al. (2001).

The sanitary and household paper sector has experienced the highest rate of growth amongst the six categories identified in Sundin et al. (2001) - a global increase of 57 per cent between 1987 and 1996, commanding a market share of 7 per cent of all paper products in 1995 (Sundin et al., 2001: 93). Sanitary paper is unique in that it does not require a separate converting facility, being able to be converted into recyclable material in a paper mill, with strength and softness enhanced through the addition of virgin pulp (Sundin et al., 2001: 93). The toilet paper and paper towel consumption of the 19.9 million urban Australians (Trading Economics, 2012) may be extrapolated from a case study of Fenner Hall. As confirmed by Fenner administration staff (2012), the Fenner Hall community houses 507 students on 20 floors in two towers, served by 61 toilets (an assortment of male, female and unisex bathrooms), 18 kitchenettes and a large shared kitchen on the ground floor. The sanitary paper products examined were produced by Kimberly-Clark and branded Scott for the toilet paper and Kleenex (Optimum Towel) for the paper towels. According to its website, Kimberly-Clark products are certified by the Forest Stewardship 
Council (FSC) as 'mixed sources', implying that 50 per cent of the pulp is obtained from FSC-accredited forests, with stringent sustainable management standards and quality control ensured through independent, third-party audits (Kimberly-Clark, 2012a, Kimberly-Clark, 2012b). The toilet paper and paper towel dispensers are refilled every morning by ISS Washroom Services cleaners contracted by Fenner Hall. The journey of the paper products, from their origin as timber in forests and plantations, to their use and disposal as either general waste or sewage is outlined in Figure 2.

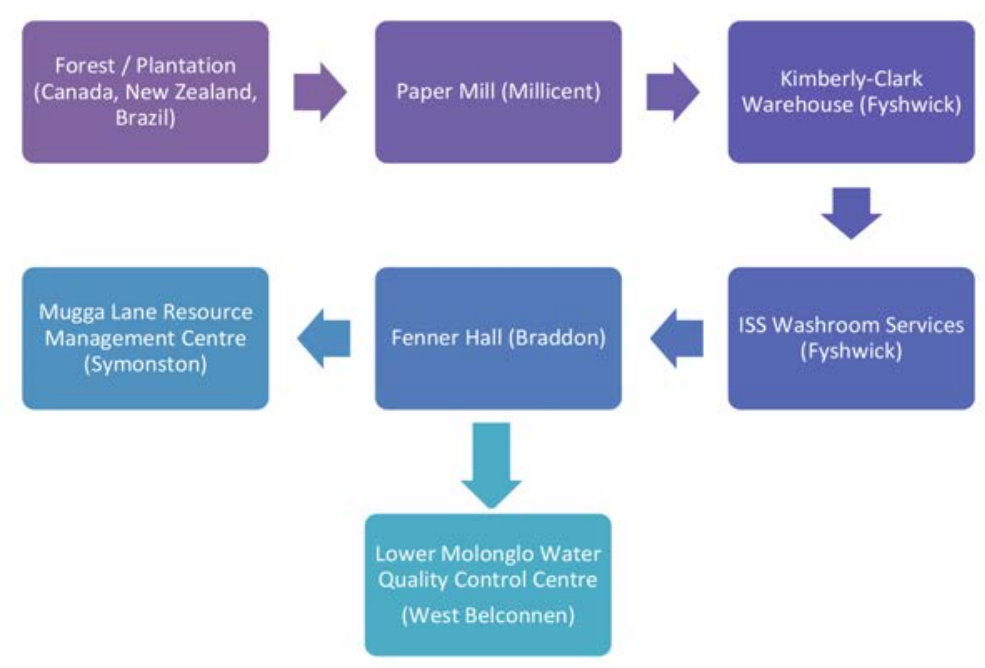

\section{Figure 2: Sanitary paper flows from production to waste management}

Source: ISS Australia (2012), Kimberly-Clark (2012b), ACTEW Water (2011), ACT TAMS (2006).

The timber for Kimberly-Clark Australia and New Zealand paper products is sourced from forests and plantations in Canada, New Zealand and Brazil (Kimberly-Clark, 2012b). The fibres are transported to the firm's paper mill in Millicent, South Australia, where toilet paper and paper towels are produced from wood pulp (Kimberly-Clark, 2012b, Sundin et al., 2001). After packaging, they are transported to the Kimberly-Clark warehouse in Fyshwick, Canberra, and then distributed to homes and businesses - in Fenner Hall's case, to ISS Washroom Services, also located in Fyshwick (ISS Australia, 2012, KimberlyClark, 2012b). Staff of the company refill the toilet paper and paper towel dispensers at Fenner Hall on a daily basis. It is expected that toilet paper will be used for personal hygiene following defecation or urination and the paper towels will be used in the kitchens and for drying hands in the bathrooms. It 
is at this point that the journeys of the two sanitary paper products diverge. Toilet paper is flushed into the sewerage system, ending up at Canberra's Lower Molonglo Water Quality Control Centre in West Belconnen, where the solid 'sewage sludge' is removed and incinerated in a high temperature furnace. The resulting Agri-Ash is sold to farmers in the region as a soil conditioner (ACTEW Water, 2011). Paper towels are primarily disposed of as general waste, entering the Fenner Hall dumpster and then sent by garbage truck to the Mugga Lane Resource Management Centre in Symonston. In 2010-11, approximately 268,000 tonnes of waste were sent to landfills from the ACT and surrounding towns, such as Queanbeyan (ACT Territory and Municipal Services (TAMS), 2006).

\section{System Boundary and Methods}

A system boundary separates the internal components of a system from external entities and, in this study, is defined as Fenner Hall's physical boundary. The actors within this system comprise of Fenner Hall's 507 residents, each of whom consumes toilet paper and paper towels based on a combination of factors as depicted by the influence diagram (Fig. 3). The variables are multifarious, and may be categorised as being biological, seasonal, socio-cultural or economic. For instance, the digestive health of residents may influence the frequency of toilet visits, thereby impacting on the use of toilet paper. Similarly, climate and weather affects people's bodily fluid evaporation, thereby determining their propensity to visit the bathroom. Such seasonal influences also shape food availability, which together with residents' economic circumstance and cooking styles, dictate the need to use paper towels. Perhaps the most crucial determinant of sanitary paper consumption, however, is the environmental awareness of the residents. This is the only factor that leads residents to make a deliberate and conscious decision regarding their use of toilet paper and paper towels. 


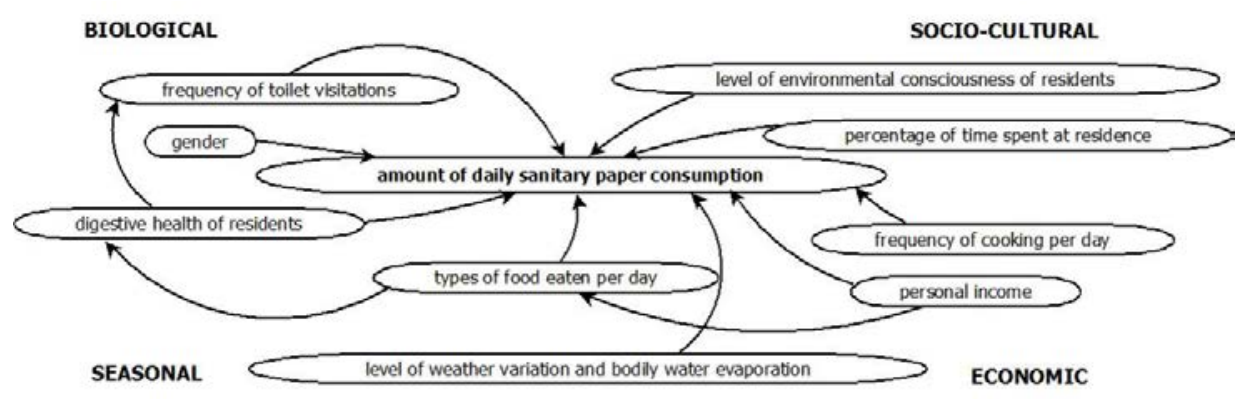

Figure 3: Influence diagram depicting variables shaping sanitary paper consumption (text represents variables whilst arrows represent processes)

Source: Author's own work.

It is beyond the scope of this essay to examine the full spectrum of variables governing the dynamics of the Fenner Hall system. Rather, this study focuses on the key variable of toilet paper and paper towel consumption, using a combination of quantitative and qualitative research methods. Quality control was maintained in the data collection process by following a mixed-method approach to ensure that the research findings are credible. The quantitative section of the study involved data collection over a period of seven days (Monday to Sunday) in the form of measuring the height of the sanitary paper remaining in centimetres $(\mathrm{cm})$ in relation to the vertical capacity of the dispenser, thereby informing the height of paper used (Fig. 4). By comparing this with the paper products original packaging, the number of toilet paper and paper towel sheets could then be determined, and the mass of paper used obtained to provide information on the sanitary paper consumption of Fenner Hall residents and the Australian community more broadly. 


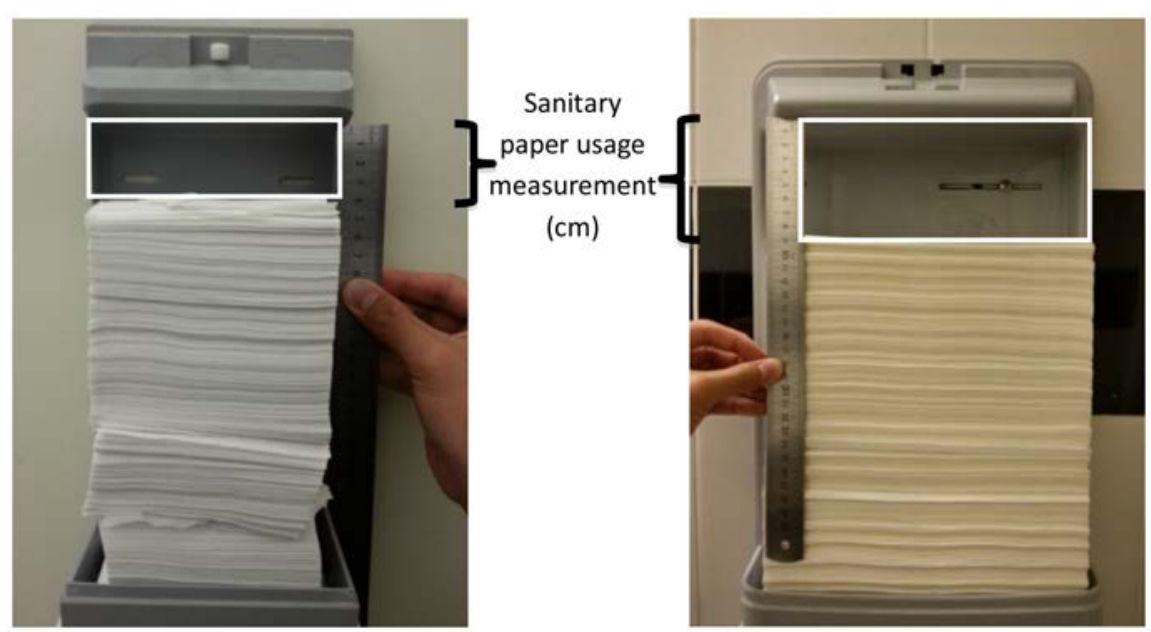

Figure 4: Measurement process of toilet paper (left) and paper towels (right)

Source: Author's own work.

Measurements were conducted at midnight so as to account for full sanitary paper consumption during the day before supplies were refilled the next morning. Due to limited human resources, three floors out of ten were randomly chosen from each of the two towers for sampling each night. Every floor consists of three bathrooms - male, female and unisex, equipped with a paper towel dispenser and a toilet paper dispenser in each of two cubicles. A kitchenette with a paper towel dispenser is also present on every floor, primarily used by residents making simple meals with the microwave or toaster. As such, ten measurements were made on each floor, except for the two ground floors, which feature a different design. North Tower ground consists of a single unisex bathroom, while South Tower ground incorporates two male and two female toilets, with neither featuring kitchenettes. Ground floor measurements also included the two male and one female toilet in the foyer, though their use of toilet rolls as opposed to interleaved tissues prevented the sampling of their toilet paper usage. The ground floor kitchens were also surveyed each night, with four out of 13 paper towel dispensers randomly chosen for measurement. The data collection method featured in this study systematically surveyed a sample of 30 per cent for a sevenday period, ensuring an adequate sample size and allowing comparisons to be made between genders, and between weekdays and weekends. 
The study conducted also involved a modest qualitative element, involving informal unstructured interviews with the ISS Washroom Services cleaners (2012) and the Fenner Hall administration staff (2012). Comments were sought from the ISS cleaners on the dynamics of toilet paper and paper towel refill processes for each floor every day, as well as for general information about their organisation and their sanitary paper supplier. Interviews with Fenner Hall administration staff involved confirming the number of residents housed, and nuances regarding the contract with ISS Washroom Services. Naturally, the data collection process also encompassed observations, particularly seeking patterns of consumption, users' attitudes, as well as any material espousing environmental awareness, such as from ANUgreen, the university division working to reduce the collective environmental impacts of students and staff (ANUgreen, 2012).

\section{Data Analysis and Discussion}

This section conducts a close study of stocks and flows of toilet paper and paper towels. It first discusses the input flows, namely wood harvesting, raw material processing, pulpwood shipping and paper production, and then examines the stocks and processes which take place within Fenner Hall, with an analysis of the data collection. Finally, measurement of the output flows concerning waste management at the Mugga Lane Resource Management Centre (Symonston) and the Lower Molonglo Water Quality Control Centre (West Belconnen) are presented.

\section{Input Flows}

The transportation distance in the life cycle of the Scott toilet paper and Kleenex (Optimal Towel) paper towels found at Fenner Hall were estimated using the Geographic Information System DistanceFromTo (2012). KimberlyClark products in Australia and New Zealand began their journey as wood in the forests and plantations of Canada, New Zealand or Brazil (Kimberly-Clark, 2012b). Assuming direct transport to the firm's paper mill in Millicent, the pulpwood would have travelled an estimated distance of 14,800 kilometres $(\mathrm{km}), 3000 \mathrm{~km}$ and 14,100 km respectively (Kimberly-Clark, 2012a, KimberlyClark, 2012b). It is most likely that the subsequent journey of the resulting toilet paper and paper towels took place by road and, given the indirect nature of road networks, 130 per cent of the geodesic distance has been used in this analysis to account for this. As such, the sanitary paper travelled $1137 \mathrm{~km}$ from Millicient to the Kimberly-Clark warehouse in Fyshwick (Kimberly-Clark, 2012a, Kimberly-Clark, 2012b). Following this, the paper products are likely to have travelled another kilometre to the ISS Washroom Services facility, also in Fyshwick, before journeying the final $12 \mathrm{~km}$ to Fenner Hall in Braddon (ISS 
Australia, 2012). In total, the sanitary paper was transported an average distance of $11,780 \mathrm{~km}$ from its origin to the point of final use, demonstrating the global scale of supply chain networks.

It is likely that the pulpwood was transported to the paper mill in Millicent by cargo ship, before being sent to Canberra on a container truck, and then moved to Fenner Hall by van, all of which are modes of transport requiring the use of fossil fuels. Fossil fuel use induces social, economic and environmental consequences deemed to be strongly negative, with severe impacts for health, energy security and climate change. Indeed, the transportation sector accounts for 25 per cent of global energy demand and 55 per cent of yearly oil consumption, resulting in direct, indirect and cumulative externalities estimated to cost the world economy more than US\$1 trillion per year (Rodrigue et al., 2009). Evidently, the input process for the toilet paper and paper towels at Fenner Hall involves significant transportation and fossil fuel use, with ramifications for the triple bottom line objectives of social, economic and environmental sustainability.

\section{Stocks and Flows}

The stocks and flows of sanitary paper use at Fenner Hall in terms of the consumption of toilet paper and paper towels constituted the fieldwork component of this study. By extrapolating from the data collected, the total consumption of sanitary paper at Fenner Hall was found to be 12.1 tonnes annually, with an average daily consumption of 70 grams per resident (Table 1). To sustain the flows within the system, Fenner Hall must maintain stocks of approximately 36 kilograms (kg) of sanitary paper daily - $11 \mathrm{~kg}$ of toilet paper and $25 \mathrm{~kg}$ of paper towels. These significant figures have adverse economic and environmental impacts (see Sundin et al., 2001) and may, in part, be attributable to toilet paper and paper towels being free resources for all 507 residents.

Table 1: Personal and annual sanitary paper consumption at Fenner Hall, 2012

\begin{tabular}{|l|l|l|l|l|}
\hline \multirow{2}{*}{ Items } & \multicolumn{3}{|l|}{ Personal consumption } & \multicolumn{2}{l|}{ Total consumption at Fenner Hall } \\
\cline { 2 - 5 } & Daily $(\mathrm{g})$ & Annual $(\mathrm{kg})$ & Daily $(\mathrm{kg})$ & Annual (tonnes) \\
\hline Toilet paper & 21 & 7.4 & 11 & 3.7 \\
\hline Paper towel & 49 & 16.5 & 25 & 8.4 \\
\hline Total & $\mathbf{7 0}$ & $\mathbf{2 4}$ & $\mathbf{3 6}$ & $\mathbf{1 2 . 1}$ \\
\hline
\end{tabular}

Source: Author's own work.

The above estimations are based on information provided on the original packaging of the Scott toilet paper and Kleenex (Optimal Towel) paper towels 
The ANU Undergraduate Research Journal

studied. Figures on the personal and total consumption of sanitary paper daily and annually were calculated from the height and weight of each paper product, measured in centimetres and grams respectively (Table 2).

\section{Table 2: Sanitary paper package details}

\begin{tabular}{|l|l|l|}
\hline Items & Original packages & Mass \\
\hline Toilet paper & 500 sheets $/ 10 \mathrm{~cm}$ height & $175 \mathrm{~g}$ \\
\hline Paper towel & 120 sheets $/ 13 \mathrm{~cm}$ height & $225 \mathrm{~g}$ \\
\hline
\end{tabular}

Source: Author's own work.

It is worth noting that gender acts as an influential factor determining the daily consumption of sanitary paper. As illustrated in Figure 5, female sanitary paper consumption is on average some 25 to 50 grams higher per day than male.

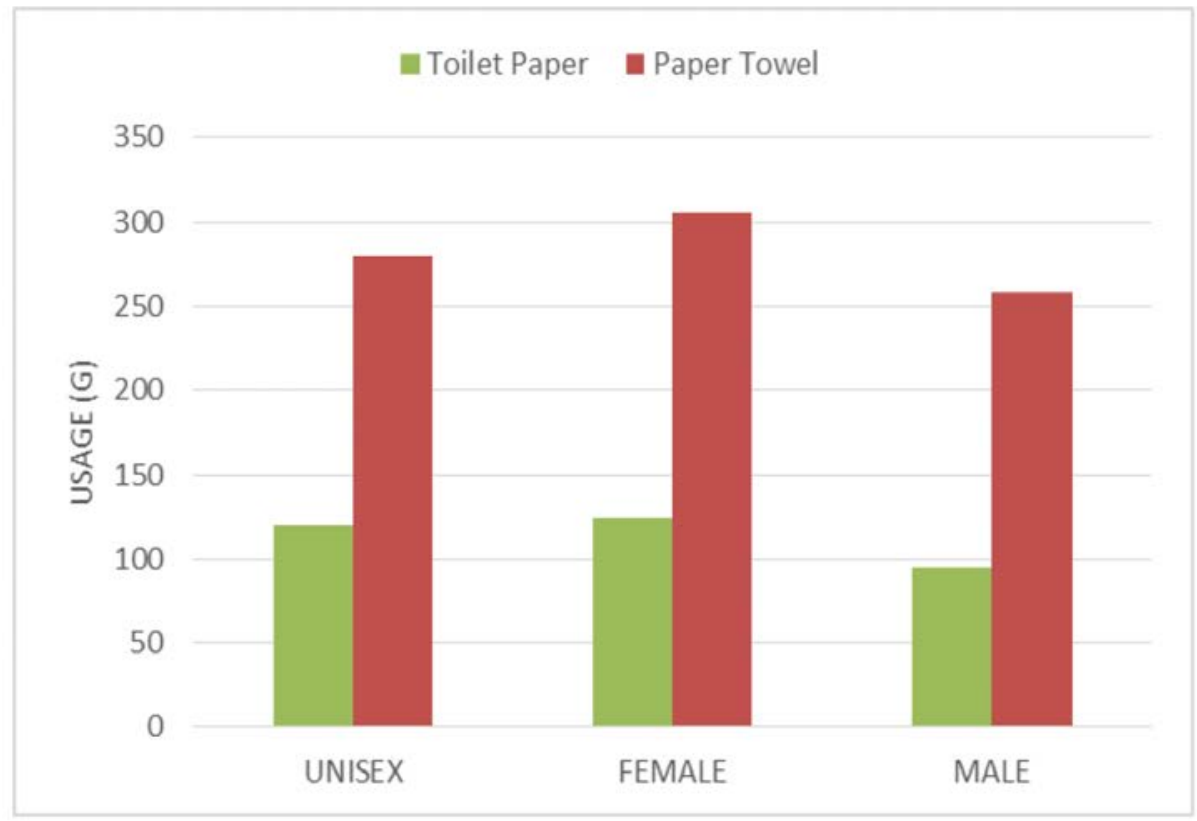

\section{Figure 5: Comparison of average daily consumption of sanitary paper in the floor bathrooms by gender}

Source: Author's own work.

Clearly, the highest proportion of sanitary paper consumption was found in female bathrooms, followed by the unisex and male bathrooms. It appears that biological differences and gender-based needs are a source of influence on sanitary paper consumption, though a more rigorous statistical analysis is 
required to verify this. Indeed, this gendered paper consumption pattern may also be the result of variations in personal hygiene habits and environmental consciousness. Evidently, only the latter two factors are manageable by policy makers, though their importance in the mix of variables that account for gender consumption differences remains unclear.

A day-by-day comparison was also drawn to display the variation of toilet paper and paper towel consumption over a period of one week (Figure 6).

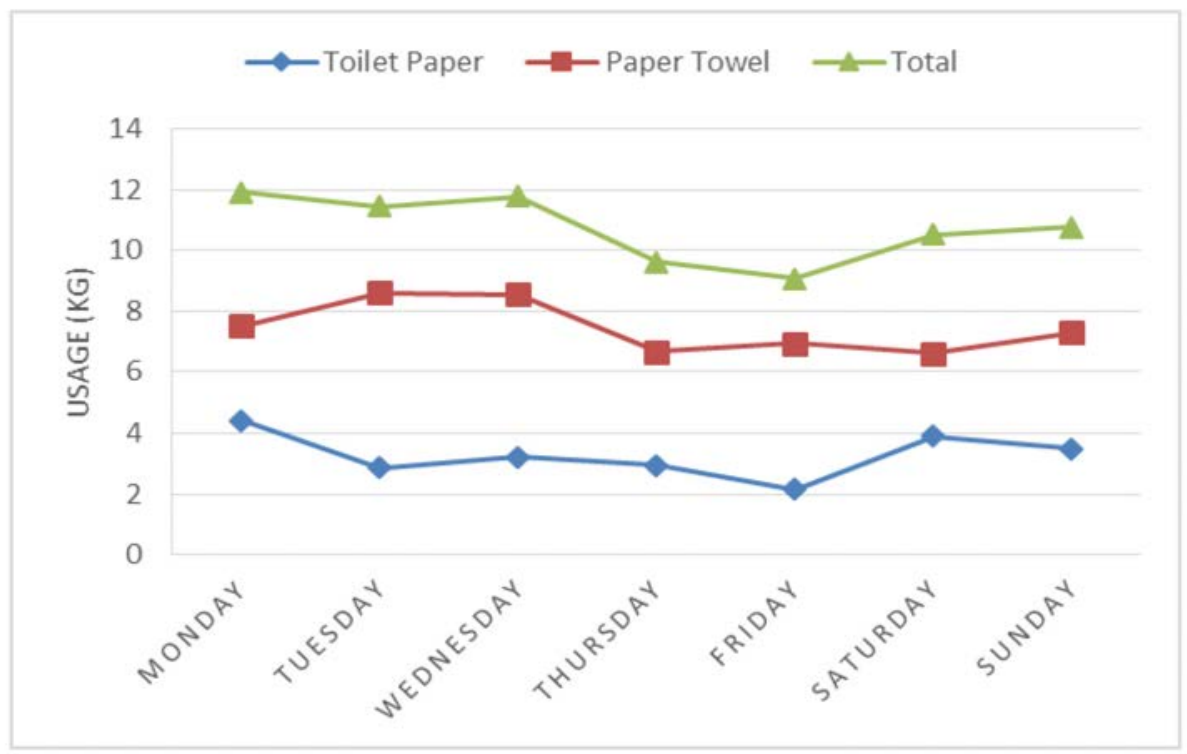

Figure 6: Day-by-day breakdown of sanitary paper usage

Source: Author's own work.

As depicted by the graph, the highest consumption of sanitary paper was found on Monday, with a usage of nearly $12 \mathrm{~kg}$, while Friday constituted the lowest consumption, it being some 30 per cent lower than that of Monday. Indeed, the total daily sanitary paper consumption remained high from Monday to Wednesday, dropping on Thursday and Friday, before rebounding over the weekend. Based on the experiences and observations made by the researchers, who also reside at Fenner Hall, such variations may be attributable to the majority of residents maintaining a regular study and cooking regime from Monday to Wednesday. Towards the end of the working week, many residents have fewer, if any, contact hours at the university and may dine outside and party from the evenings until the early mornings. Such patterns reduce the frequency of kitchen and bathroom visits, which is particularly pertinent towards the evening. Over the weekend, some residents may stay at Fenner Hall and maintain the usual 
frequency of cooking and toilet usage, whilst other residents may take leave from Fenner Hall for one or two days, thereby explaining the gradual rebound of the sanitary paper consumption depicted in Figure 6.

As the influence diagram (Fig. 3) previously demonstrated, a multitude of biological, seasonal, socio-cultural and economic variables interact with one another to determine the flows in the system; i.e. the consumption of toilet paper and paper towels. The stocks of the daily 36 tonnes of sanitary paper consumption, and by extension, the annual 12.1 tonnes, are shaped by both internal and external factors. As such, it is imperative to acknowledge the interconnectedness and complexity of the studied system, recognising the need for systems thinking to change the complex stocks and flows of sanitary paper consumption.

In general, the stocks and the consumption processes of toilet paper and paper towels at Fenner Hall remain significant in spite of the mild variations between gender and the days of the week. It is necessary to note that both the 70 grams per resident and the total $36 \mathrm{~kg}$ of daily sanitary paper consumption are considerable rates of flow. As such, there is scope for a more detailed investigation into Fenner Hall residents' sanitary paper consumption behaviours and patterns. Having a more nuanced understanding of such stocks and processes could inform policies to reduce toilet paper and paper towel use at Fenner Hall, with implications for the Fenner Hall budget and the environment more broadly.

\section{Output Flows}

Given that toilet paper is used for personal hygiene following defecation or urination, and paper towels are for kitchen use and for drying hands, their methods of disposal are different, resulting in a divergence in the journeys made by these two sanitary paper products. After being flushed from the toilet bowl, toilet paper then enters the sewerage system, being conveyed by wastewater an estimated distance of at least $19 \mathrm{~km}$ to arrive at the Lower Molonglo Water Quality Control Centre in West Belconnen (ACTEW Water, 2011). This sewage is then treated, with the liquid effluent either reused for public garden irrigation, or reentering the Molonglo River, flowing downstream into the Murrumbidgee outside the city. The water then joins the Murray-Darling River, before emptying into the ocean at Lake Alexandrina in South Australia. The majority of toilet paper, however, will remain in solid form and be removed as 'sewage sludge', incinerated and then sold to farmers as fertiliser (ACTEW Water, 2011).

Used paper towels are disposed of in the waste bins found in the bathrooms, kitchenettes and the ground floor kitchen at Fenner Hall. ISS Washroom Services cleaners collect these and move them to the Fenner Hall dumpster, which is located behind the main kitchens. This general waste is removed by 
waste collectors in garbage trucks, and travels at least $16 \mathrm{~km}$ from Braddon to the Mugga Lane Resource Management Centre in Symonston (ACT TAMS, 2006). The waste may undergo some processing, but is ultimately compacted and buried, decomposing slowly due to a lack of oxygen and moisture. As such, the annual consumption of paper towels at Fenner Hall of some 8.4 tonnes has a significant environmental impact, with consequences for surface water, groundwater, flora, fauna, air quality and noise (South Australian Environment Protection Authority, 2007). The environmental ramifications of Fenner Hall's 3.7 tonnes of annual toilet paper consumption are, however, somewhat mitigated by the reuse of 'sewage sludge' in farming (ACTEW Water, 2011), though the incineration process does generate emissions and toxins. Fine particulate matters produced near incinerators have been found to increase morbidity and mortality through cancer, birth defects and heart disease (Thomson and Anthony, 2005).

\section{Implications for Urban Australia}

Although this material stocks and flows analysis was conducted through a case study of Fenner Hall, its findings regarding toilet paper and paper towel consumption may be used to obtain an order of magnitude estimate encompassing all 19.9 million urban Australians (Trading Economics, 2012). Drawing on the figures in Table 1, it has been found that urban Australians consume a total of 1400 tonnes of sanitary paper daily and 511,000 tonnes annually. This number was devised through simple numeric extrapolation, on the assumption that Fenner Hall residents are roughly typical in their consumption patterns. Such large figures embody the realities of the modern growth economy, based on perpetual increases in the production and consumption of goods and services, bringing to light the social, economic and environmental consequences of the market system. To alter the material flows of products in the Australian economy, governments may implement market-based policy instruments or legislate regulatory measures to internalise negative externalities. In recent times, however, there have been renewed calls to foster cultural change, managing demand by raising environmental awareness, aided by actors like governments, non-governmental organisations and community groups. In the case of Fenner Hall, ANUgreen and the Fenner Hall Administration Office have attempted to build residents' environmental consciousness through heightened awareness of their electricity and water usage.

There is scope to expand this program to encompass the nuances of toilet paper and paper towel consumption by targeting the potential gender-based consumption patterns and residents' personal habits. For instance, an inter-floor competition could be held, with a prize awarded at the end of the semester to the floor using the least amount of sanitary paper. Naturally, the feasibility of 
such exercise is dependent on human resources and the propensity for residents to sabotage the competition. This final notion regarding the importance of collectivism in solving complex environmental problems also grounds the study conducted with theoretical significance. As toilet paper and paper towels are provided free of charge at Fenner Hall, there is reason to believe that their consumption may suffer from the 'tragedy of the commons' (Hardin et al., 1973). As non-excludable, but rival products, each resident has an incentive to consume the sanitary paper as rapidly as possible before it is used up. One way to counter this tendency would be to offer sanitary paper at a fee. This is particularly pertinent for paper towels in the ground floor kitchen, which was found to have been frequently left with little or no stocks at the end of each day. Paper towel is, however, a discretionary commodity, being easily replaceable with the alternative of cloth towels and is hence an easier target for instituting social change. Nevertheless, potential future projects may involve interdisciplinary research with economists and psychologists to further understand the dynamics of human behaviour. As such, this material stocks and flows analysis has served not only a practical, but also theoretical significance, offering itself as a springboard for further research projects.

\section{Limitations}

The study faced potential methodological weaknesses during fieldwork and data analysis, including both random and systematic errors. Firstly, human error may have resulted in inaccurate measurements during the data collection process - a particular concern being parallax error when reading off the height of sanitary paper used. Fatigue may have contributed to transcription errors, which would have impacted on the reliability of the results, with ramifications for data analysis and the implications drawn.

Such challenges are coupled with issues in statistical inference, namely in making generalisations about the Fenner Hall community and urban Australians more broadly. In each of the seven days, six of the 20 floors and four of the 13 dispensers on the ground floor kitchen were surveyed, raising the question of whether our sample size is sufficient to be representative. In the same way, it is unknown whether a consecutive seven-day study period in early November 2012 can illustrate the average sanitary paper consumption of Fenner Hall residents, particularly given that the study was conducted during students' preparation period for examinations. They may have had a lower propensity to cook, resulting in skewed paper towel consumption figures. As noted in the influence diagram (Fig. 3), there is a seasonal influence upon sanitary paper consumption, as average daily temperatures can impact upon residents' bodily fluid evaporation, thereby altering their toilet visitation patterns. It must also be 
noted that as Fenner Hall residents are from interstate or overseas, the majority are in residence for a period of nine months during the academic year only, and so the aforementioned yearly sanitary paper consumption figures may not have represented the reality consumed. Finally, the study did not account for residents who chose to purchase their own sanitary paper or use cloth towels as opposed to paper towels for cooking purposes, such as drying dishes or mopping up spills.

These random errors are also coupled with potential systematic errors. Indeed, the measured height of sanitary paper, conducted at midnight, may not have corresponded to the actual use of toilet paper and paper towels. According to the interview with ISS Washroom Services cleaners (2012), they refilled the dispensers only in the mid-morning, offering a window for residents to use sanitary paper in the early morning, which would not have been captured in this study. Although this limitation was made note of during the study's design phase, it appeared inevitable due to practicality and the time constraints of the researchers in the data collection process.

Another point of contention arises from the use of the toilet paper and paper towel consumption figures of Fenner Hall residents to make generalisations about the broader urban Australian community. Much like the notion of 'aggregation bias' as described in Ewing and Cervero (2010), making inferences about the aggregate from the individual may be problematic for a range of reasons. One is that the lifestyle choice of university students may differ from that of typical Australians, with people from the targeted age group perhaps being more prone to wasteful consumption. It has been argued, however, that the younger generation is also more environmentally conscious, and hence the impact of the studied demographic on the aggregated results remains unclear. Moreover, some 50 per cent of Fenner Hall residents are international students, with cultural differences having the potential to shape their sanitary paper consumption, thereby contributing to the complexity of this exercise.

\section{Conclusion}

This material stocks and flows analysis examines the consumption of toilet paper and paper towels in the urban context of the Fenner Hall residential college. This essay presents the input flows of the material, namely wood harvesting, raw material processing, pulpwood shipping and paper production, before conducting a seven-day data collection process to estimate daily sanitary paper consumption to be 70 grams per resident and annual consumption to be 12.1 tonnes for the entire residence. The study then examines the output flows of toilet paper through the sewerage system, and paper towels through general waste collection. 
This essay offers a glimpse of the interdependence of the biological, seasonal, socio-cultural and economic variables, thereby supporting the nuances of the influence diagram presented (Fig. 3), emphasising the importance of systems thinking. The essay acknowledges humanity's need to alter flows, and proposes economic, political and cultural instruments to bring about this change. It then presents the potential weaknesses and limitations of the research conducted, giving grounds for review and improvement. In conclusion, the urban system is complex and interconnected, due to it being of a heavily human-modified nature. Australians' high use of sanitary paper stems from it being seen as an indispensable part of modern daily life, which together with the consumption of other such goods and services, results in the intensive utilisation of ecosystem services. Only a transformational change which closes the loop in the life cycle of material stocks and flows by reducing materials can enrich our cities, moving them towards the triple bottom line objectives of social, economic and environmental sustainability.

\section{Acknowledgements}

We would like to thank Dr Rob Dyball for conceptual assistance during the course of this project and Dr Barry Newell for his constructive advice on the crucial revisions made to this essay. The useful suggestions from Professor Steve Dovers and Brendan Moloney are also very much appreciated. Finally, we thank all 507 residents of Fenner Hall for putting up with our presence on many late nights and for intruding on their bathroom activities. 


\section{Appendix: Summary of Raw Data from Day 1 to Day 7}

\begin{tabular}{|c|c|c|c|c|c|}
\hline & & Toiet Paper & Kitchen Paper & & Length \\
\hline & Unisex & $81.5(-1)$ & 98.5 & & \\
\hline \multirow[t]{4}{*}{ Monday } & Female & 85 & 104.5 & Sum & \\
\hline & Male & 86 & 96 & Toilet Paper & 252.5 \\
\hline & Kitchen & & 135 & Kitchen Paper & 434 \\
\hline & Unisex & $75(-1)$ & 112 & & \\
\hline \multirow[t]{4}{*}{ Tuesday } & Female & 91 & 139 & Sum & \\
\hline & Male & 72 & 110.5 & Toilet Paper & 163 \\
\hline & Kitchen & & 136 & Kitchen Paper & 497.5 \\
\hline & Unisex & $76.5(-2)$ & 94 & & \\
\hline \multirow[t]{4}{*}{ Wednesday } & Female & $70(+1)$ & 122.5 & Sum & \\
\hline & Male & $37(+2)$ & 142 & Toilet Paper & 183.5 \\
\hline & Kitchen & & 136 & Kitchen Paper & 494.5 \\
\hline & Unisex & $59(-1)$ & 80.5 & & \\
\hline \multirow[t]{4}{*}{ Thursday } & Female & 89 & 103.5 & Sum & \\
\hline & Male & 79.5 & 75.5 & Toilet Paper & 168.5 \\
\hline & Kitchen & & 126 & Kitchen Paper & 385.5 \\
\hline & Unisex & 67 & 92.5 & & \\
\hline \multirow[t]{4}{*}{ Friday } & Female & $77(-1)$ & 103 & Sum & \\
\hline & Male & 56 & 71 & Toilet Paper & 123 \\
\hline & Kitchen & & 134 & Kitchen Paper & 400.5 \\
\hline & Unisex & 71 & 94.5 & & \\
\hline \multirow[t]{4}{*}{ Saturday } & Female & 88 & 91.5 & Sum & \\
\hline & Male & 63.5 & 64.5 & Toilet Paper & 222.5 \\
\hline & Kitchen & & 132 & Kitchen Paper & 382.5 \\
\hline & Unisex & 105.5 & 93.5 & & \\
\hline \multirow[t]{3}{*}{ Sunday } & Female & 94 & 97.5 & Sum & \\
\hline & Male & $61.5(-1)$ & 94 & Toilet Paper & 199.5 \\
\hline & Kitchen & & 136 & Kitchen Paper & 421 \\
\hline
\end{tabular}


The ANU Undergraduate Research Journal

\section{Bibliography}

ACT TAMS. (2006). Mugga Lane Resource Management Centre. Retrieved 11 November 2012 from http://www.tams.act.gov.au/live/recycling-waste/ centres/mugga_lane_landfill_symonston.

Actew Water (2011). Lower Molonglo Water Quality Control Centre. Retrieved 10 November 2012 from http://www.actew.com.au/Water\%20and\%20 Sewerage \% 20Systems/ACT \% 20Sewerage \% 20System/What \% 20is \% 20 sewerage/Sewage \% 20Treatment \% 20Plants/Lower \% 20Molonglo\% 20 Water\%20Quality\%20Control\%20Centre.aspx.

ANUgreen (2012). About ANUgreen. Retrieved 10 November 2012, from http:// sustainability.anu.edu.au/about-anugreen.

Bai, X., Roberts, B., \& Chen, J. (2010). 'Urban sustainability experiments in Asia: patterns and pathways.' Environmental Science \& Policy, 13(4), 312-325.

DistanceFromTo (2012). Retrieved 10 November 2012 from http://www. distancefromto.net/.

Ewing, R. \& Cervero, R. (2010). 'Travel and the Built Environment - A MetaAnalysis.' Journal of the American Planning Association, 76, 265-294.

Fenner Administration Office (2012). pers. comm., Relevant information about Fenner Hall. Canberra.

Hardin, G. (1968). 'The Tragedy of the Commons.' Science, 162, 1243-1248.

ISS Australia (2012). 'ISS Washroom Service Australia.' Retrieved 10 November 2012 from http://www.au.issworld.com/Pages/Frontpage.aspx.

ISS Washroom Services Cleaners (2012), pers. comm., Relevant information about sanitary paper consumption in Fenner Hall. Canberra.

Kimberly-Clark (2012). 'Kimberly-Clark Environmental Management System.' Retrieved 10 November 2012 from http://www.kimberly-clark.com.au/en/ sustainability/planet/environmental-management/.

Kimberly-Clark (2012). 'Kimberly-Clark Use of Renewable Fibres.' Retrieved 8th November 2012 from http://www.kimberly-clark.com.au/en/sustainability/ planet/fibre-source/. 
Martin, S. (2007). 'Paper Chase.' Retrieved 10 November 2012 from http://www. ecology.com/feature-stories/paper-chase/index.html.

Paper on Web (2012). 'Typical Density of Some Papers.' Retrieved 10 November 2012 from http://www.paperonweb.com/density.htm.

Rodrigue, J. P., Comtois, C., \& Slack, B. (2009). The Geography of Transport Systems. Routledge.

Southern Australian Environmental Protection Authority. (2007). 'Environmental management of landfill facilities (municipal solid waste and commercial and industrial general waste).' Retrieved from http://www.epa.sa.gov.au/xstd_ files/Waste/Guideline/guide_landfill.pdf

Sundin, E., Svensson, N., McLaren, J., \& Jackson, T. (2001). 'Materials and Energy Flow Analysis of Paper Consumption in the United Kingdom, 1987-2010.' Journal of Industrial Ecology, 5(3), 89-105.

Thompson, J., \& Anthony, H. (2005). 'The Health Effects of Waste Incinerators.' Journal of Nutritional and Environmental Medicine, 15(2-3), 115-156.

Trading Economics (2012). 'Urban Population in Australia.' from http://www. tradingeconomics.com/australia/urban-population-wb-data.html.

UNICEF (2012). The State of the World's Children 2012: Children in an Urban World. New York: UNICEF

Ververis, C., Georghiou, K., Christodoulakis, N., Santas, P., \& Santas, R. (2004). "Fiber dimensions, lignin and cellulose content of various plant materials and their suitability for paper production." Industrial Crops and Products, 19(3), 245-254. 
This text taken from The ANU Undergraduate Research Journal Volume Five 2013, published 2014 by ANU Press, The Australian National University, Canberra, Australia. 